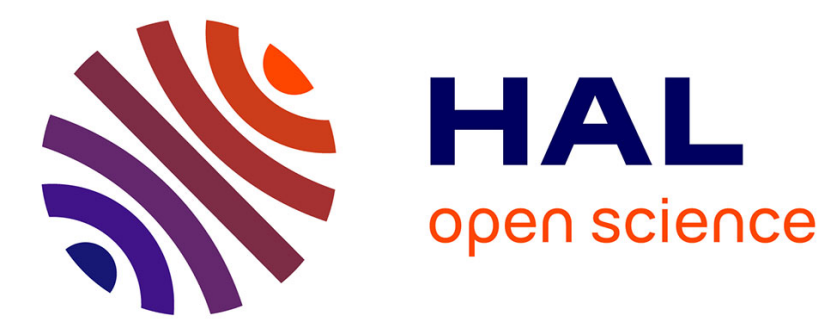

\title{
STRUCTURE AND LOCAL ORDER IN AMORPHOUS Si1-x SNx SEMI-CONDUCTOR
} ALLOYS

M. Vergnat, M. Piecuch, J.-F. Geny, C. Mourey, G. Marchal, M. Gerl

\section{- To cite this version:}

M. Vergnat, M. Piecuch, J.-F. Geny, C. Mourey, G. Marchal, et al.. STRUCTURE AND LOCAL ORDER IN AMORPHOUS Si1-x SNx SEMI-CONDUCTOR ALLOYS. Journal de Physique Colloques, 1985, 46 (C8), pp.C8-287-C8-291. 10.1051/jphyscol:1985842 . jpa-00225185

\section{HAL Id: jpa-00225185 https://hal.science/jpa-00225185}

Submitted on 1 Jan 1985

HAL is a multi-disciplinary open access archive for the deposit and dissemination of scientific research documents, whether they are published or not. The documents may come from teaching and research institutions in France or abroad, or from public or private research centers.
L'archive ouverte pluridisciplinaire HAL, est destinée au dépôt et à la diffusion de documents scientifiques de niveau recherche, publiés ou non, émanant des établissements d'enseignement et de recherche français ou étrangers, des laboratoires publics ou privés. 
JOURNAL DE PHYSIQUE

Colloque C8, supplément au $n^{\circ} 12$, Tome 46, décembre 1985

page $\mathrm{C} 8-287$

STRUCTURE AND LOCAL ORDER IN AMORPHOUS $S_{1-X} \mathrm{SN}_{\mathrm{X}}$ SEMI-CONDUCTOR ALLOYS

M. Vergnat, M. Piecuch, J.-F. Geny, C. Mourey, G. Marcha1 and M. Ger1

Laboratoixe de Physique du Solide, (U.A. au C.N.R.S. no 155),

Université de Nancy I, B.P. 239, 54506 Vandoeuvre lès Nancy cedex, France

Résumé - La structure atomique d'alliages amorphes $S i_{1-x} S n_{X}(x=0$ à 0,50$)$ obtenus par coévaporation sous ultravide a été étudiée par diffraction électronique, spectrométrie Mössbauer et mesures de densité. Ies alliages montrent une nette tendance à l'ordre, les atomes d'étain évitant de se placer en position de proches voisins pour des raisons d'encombrement stérique. L'analyse des spectres Mössbauer en fonction de la température donne des informations sur le spectre de vibration des noyaux ${ }^{119} \mathrm{Sn}$.

Albstract - The atomic structure of co-evaporated amorphous $\mathrm{Si}_{1-\mathrm{x}} \mathrm{Sn}_{\mathrm{x}}$ alloys has been studied by electron diffraction, Mössbauer spectroscopy and density measurements. The alloys show a tendency to ordering, $\mathrm{Sn}$ atoms avoiding to be in close contact. The analysis of the temperature change of Mössbauer spectra provides some information about the vibration spectrum of ${ }^{119} \mathrm{Sn}$ in the alloys.

\section{I - INTIRODUCTION}

The aim of this paper is to provide some information on the structure of $\mathrm{Si}_{1-\mathrm{x}} \mathrm{Sn}_{\mathrm{x}}$ amorphous alloys by means of diffraction experiments, density and hyperfine parameters measurements, in order to obtain a coherent picture of their atomic structure. The random network model of Polk / $1 /$ and the model developed by Connell and Temkin $12 /$, based on tetrahedral units, account for the experimental observations made in amorphous group IV semi-conductors using X-ray, electron and neutron diffraction, namely $/ 3 /$ :

i) the average number of nearest neighbours to a given atom is slightly smaller than four and the $\mathrm{n}$. $\mathrm{n}$. distance is close to that observed in the crystalline phase,

in the crystal.

ii) the number of second neighbours is close to twelve, as

These models have been used to interpret the physical properties of some semi-conductor compounds /4/ and it was interesting to investigate the structure of a IV-IV amoxphous alloy in a large composition range. The Si Sn system has been chosen because it is possible to incorporate up to 50 \% of $\mathrm{Sn}$ in amorphous homogeneous Si Sn alloys. Moreover the optical band gap continuously changes with comoosition, so that it is possible, by monitoring the preparation conditions, to fabricate layers or militilayers to be used in photovoltaic conversion devices or in imaging systems.

Si Sn amorphous alloys, prepared by rf or dc sputtering, have been studied by Vérié et al. $/ 5,6 /$ and by williamson and Deb $/ 7 /$. This method of preparation leads to the introduction of gaseous impurities in the alloys, that may alter their atomic and electronic structure. In order to accurately control the purity of the samples, we have constructed an apparatus for preparing $\mathrm{Si}$ Sn amorphous alloys by co-evaporation in a high vacuum /8/. Electron diffraction, Mössbauer spectrometry experiments and density measurements have been made to investigate the structure of the amorohous films obtained by this procedure. 
II - EXPERTMFNTAL RESULTS

Sil-x $\mathrm{Sn}_{\mathrm{X}}$ samples were prepared in an ultrahigh vacuum chamber $\left(3 \times 10^{-8}\right.$ Torr $)$, by simultaneous condensation of silicon and tin on substrates held at $77 \mathrm{k}$. Two quartz monitoring systems were used to control the evaporation rate of each constituent. For $\mathrm{x}<0.5$ perfectly homogeneous amorphous alloys were obtained. In the concentration range $0.50<x<0.75$ small $\beta-$ Sn crystallites are observed, by dark field electron microscopy, in a matrix that remains amorphous. For $x>0.75$ the amorphous phase disappears and a mixture of $\beta-\mathrm{Sn}$ and Si crystallites is observed.

\section{1 - Electron diffraction}

Electron diffraction patterns have been obtained using a scanning high energy electron diffraction apparatus $19 /$. As in pure amorphous silioon or germanium, the structure factor exhibits two well-defined peaks and a third peak with a very small intensity. The ratio $y=k_{2} / k_{1}$ of the values of $k$ at the first two maxima of $s(k)$ continuously changes from $\mathrm{y}_{1}=1.81$ for pure a-Si to $\mathrm{y}_{2}=1.63$ for $\mathrm{x}=0.57$ (table $\mathrm{I}$ ). This can be taken as an indication that the atomic structure of the alloys evolves Iram a Polk-iike structure for $\mathrm{x}=0$, towards a structure where odd-membered rings are excludepd for $\mathrm{x}=0.5$. As shown in table $I$, elemental semi-conductors are correctly described by the Polk model $(y=1.80-1.82)$ while the Connell-Temkin model $(y=1.67-1.76)$ seems more appropriate for amorphous compounds.

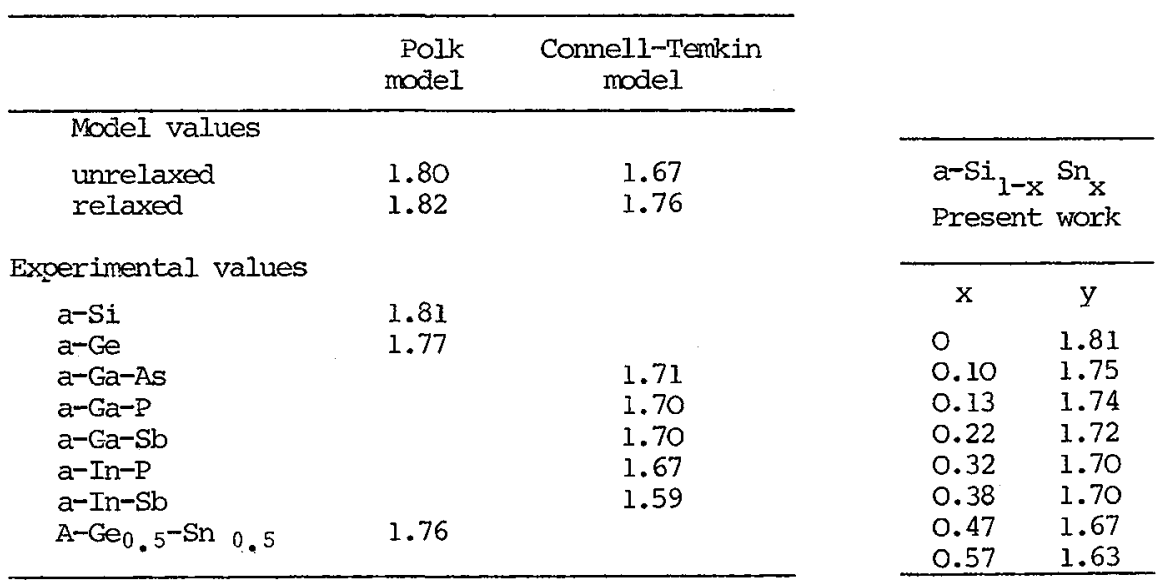

Table I - The ratio $\mathrm{y}=\mathrm{k}_{2} / \mathrm{k}_{1}$ of the values of $\mathrm{k}$ at the first and second diffraction peaks (from ref. $/ 3 /$ ).

From this discussion we can draw the conclusion that in Si Sn alloys, chemical and size constraints are large enough to induce a well-characterized chemical short range order. Sn atoms show a tendency to be selectively surrounded by Si atoms so that, as $x$ increases, the number of odd-membered rings decreases.

\section{2 - Mean interatomic distance}

The mean interatomic distance is determined as follows. The thickness of the amorphous films is measured by Tolansky interferometry and the number of atoms of each species that are deposited per unit area is determined by the frequency shift of the oscillators. Assuming a tetrahedral network it is possible to calculade $\bar{d}$ the average nearest neighbour distance ( $f i g .1) ; \bar{d}$ is found to vary linearly with $x$ from $\bar{d}=2.41$ in pure a-Si, a figure $2.5 \%$ larger than in pure C-Si. We may therefore assume that $\bar{d}$ would increase by $2.5 \%$ when (hypothetical) crystalline $\mathrm{Si}_{1-\mathrm{x}} \mathrm{Sn}_{\mathrm{X}}$ alloys are made amorphous. The interatomic distance in c-alloys would then change with $x$ 
according to curve (b) in fig. 1. The linear variation of $\bar{a}$ with $x$ is consistent with the assumption that $\mathrm{Sn}$ atoms avoid close contacts. $n i t h \mathrm{~d}_{\mathrm{SiSi}}=2.35 \AA$ as in $\mathrm{C}-\mathrm{Si}$, the experimental data lead to $d_{S i S n}=2.53 \AA$, a figure 1.5 o smaller than $1 / 2\left(a_{\text {SiSi }}+a_{S n S n}\right)$.

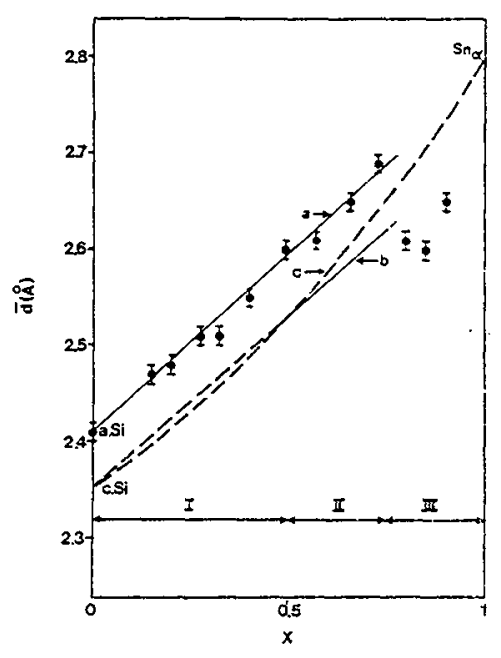

Fig. 1 - Variation with $\mathrm{x}$ of the average interatomic distance $\bar{d}$ in amorphous $S i_{1-x} S n_{x}$ alloys

\section{3 - Mössbauer spectroscopy}

Conventional transmission Mössbauer spectroscopy spectra have been obtained in the temperature range $4.2 \mathrm{~K}$ to $400 \mathrm{~K}$ in alloys of different compositions, using the ${ }^{119} \mathrm{Sn}$ resonant nucleus, with a $10 \mathrm{mCi} \mathrm{Ba} \mathrm{Sn} \mathrm{O}_{3}$ source. In amorphous alloys a single resonance line is observed, which fits accurately to a Lorentzian of FWMM $=1.16 \mathrm{~mm} . \mathrm{s}^{-1}$. This shows i) that there is only one site for $\mathrm{Sn}$ atoms in our alloys, unlike in dc sputtered alloys /7/ where the association with oxygen leads to three lines, ii) Sn atoms tend to avoic themselves because, if the distribution of $\mathrm{Sn}$ atoms were random, a broadened line would be observed.

The Debye-waller and the second-order Döppler shift have been measured as a function of temperature in three different alloys, to determine the dynamics of $\mathrm{Sn}$ atoms.

two components :

a - The total shift of the absorption line is made up of

$$
\delta_{\text {mes }}=\delta_{\text {IS }}-\frac{\left\langle\mathrm{V}^{2}\right.}{2 \mathrm{C}}>
$$

where $\delta_{I S}$, assumed to be independent of $T$, is the chemical shift and the second term is due to the second-order Döppler effect. According to the conventional theory of lattice vibrations, $\left\langle\mathrm{v}^{2}\right\rangle$ can be written;

$$
\left\langle v^{2}>=\frac{3 \hbar}{2 m} \int_{0}^{\infty} g(\omega) \operatorname{coth}\left(\frac{\hbar \omega}{2 k T}\right) \omega d \omega\right.
$$

our results show that the density of states $g(\omega)$ (normalized to unity) can be approximated by a superposition of a Debye band with Debye frequency $\omega_{D}$, and an Einstein
level at the frequency $\omega_{E}$ : 


$$
g(\omega)=\frac{3}{2} \frac{\omega^{2}}{\omega_{D}^{3}}\left(1-Y\left(\omega-\omega_{D}\right)\right)+\frac{1}{2} \delta\left(\omega-\omega_{E}\right)
$$

where $y$ is the heaviside function.

In order to determine $\delta_{\mathrm{IS}}$, we notice that the Debye band contributes by $3 \mathrm{kI} / 4 \mathrm{mc}$ to $\delta_{\text {mes }}$ at high temperature. A plot of

$$
-y=\delta_{\text {mes }}+\frac{3 \mathrm{kT}}{4 \mathrm{mC}}+\frac{3 \hbar \omega_{E}}{8 \mathrm{mC}} \operatorname{coth} \frac{\hbar \omega_{E}}{2 \mathrm{kT}}
$$

as a function of $1 / T$, extrapolated at infinite temperature, provides the value of $\delta_{I S}$. The extrapolation process is not sensitive to the value of $\omega_{E}$ and the value $\omega_{E}=8 \times 10^{13} \mathrm{~s}^{-1}$ has been selected for this purpose. According to table II $\delta_{I S}$ is observed to increase with $\mathrm{x}$, which can be ascribed to the decrease of the number of p-like electrons concentrated in covalent bonds when the concentration of tin increases.

When $\delta_{\text {IS }}$ is determined, the variation of $\left\langle v^{2}>\right.$ with $T$ can be obtained from eq. (1) (Fig. 2).
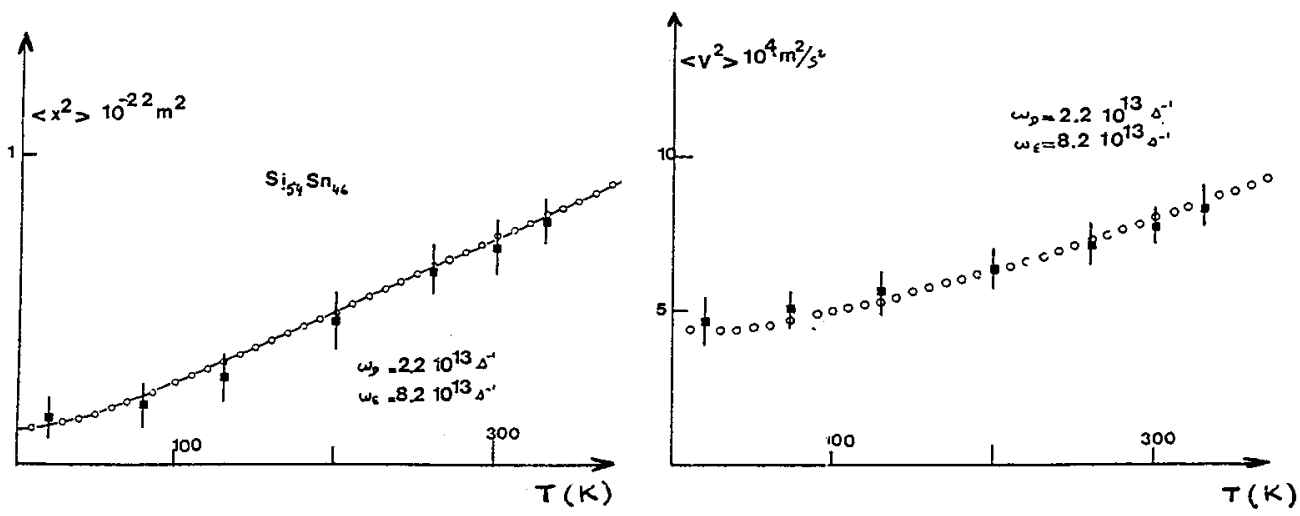

Fig. 2 - Mean square amplitude $\left(\left\langle\mathrm{x}^{2}\right\rangle\right)$ and velocity $\left.\left(<\mathrm{v}^{2}\right\rangle\right)$ of ${ }^{119}$ Sn nuclei in $\mathrm{Si}_{54} \mathrm{Sn}_{46}$ amorphous alloys.

b - The Debye-Waller factor is determined from the LambMössbauer f-factor. The intensity factor $\mathrm{E}(0)$ is defined as

$$
E(0)=\frac{I(\infty)-I(0)}{I(\infty)}
$$

where I $(\infty)$ and I $(0)$ are respectively the background intensity and the peak intensity of the absorption line. It is well known that $E(O)$ can be written :

$$
E(0)=f_{S}\left[1-e^{-0.5 T_{A}} J_{0}\left(i \quad 0.5 T_{A}\right)\right]
$$

where $\mathrm{I}_{\mathrm{S}}$ is the recoilless Eraction of the $\mathrm{Ba} \mathrm{Sn} \mathrm{O}_{3}$ source $\left(E_{\mathrm{S}}=0.6\right), \mathrm{T}_{\mathrm{A}}=\mathrm{n} \sigma_{0} f$ where $n$ is the number of resonant nuclei per unit surface, $\sigma_{0}$ is the maximal resonance cross-section and $J_{0}$ is the Bessel function of zero order. From the experimental absorption spectra we have determined $f$ and the mean-square amplitude of the oscillations of $\mathrm{Sn}$ nuclei from the equation

$$
\ln f=-k^{2}<x^{2}>
$$

where $k$ is the wave-number of the incident $\gamma$-rays. 
Experimental values of $\left\langle\mathrm{x}^{2}\right\rangle$ are given in fig. 2. For each concentration investigated the Debye and Einstein Irequencies defined by eq. (3) have been determined through a least square fitting of the experimental results to the theoretical expressions for $\left.<\mathrm{x}^{2}\right\rangle$ and $\left\langle\mathrm{v}^{2}\right\rangle$.

$$
\begin{aligned}
& \left\langle x^{2}>=\frac{\pi}{2 m} \int_{0}^{\infty} g(\omega) \operatorname{coth} \frac{\hbar \omega}{2 k T} \frac{d \omega}{\omega}\right. \\
& <v^{2}>=\frac{3 \hbar}{2 m} \int_{0}^{\infty} g(\omega) \operatorname{coth} \frac{\hbar \omega}{2 k T} \omega d \omega
\end{aligned}
$$

\begin{tabular}{|c|c|c|c|c|}
\hline $\mathrm{x}$ & $\delta_{\mathrm{mes}}(300 \mathrm{~K})$ & ${ }_{\mathrm{Im} . \mathrm{s}^{-1}}^{\mathrm{m}_{\mathrm{IS}}}$ & $10^{13} \mathrm{~s}^{-1}$ & $10^{13} s^{-1}$ \\
\hline 0.19 & 2.008 & 2.14 & $3.0 \pm 0.2$ & $8.0 \pm 0.2$ \\
\hline 0.23 & 2.016 & 2.15 & $2.1 \pm 0.2$ & $8.1 \pm 0.2$ \\
\hline 0.46 & 2.063 & 2.19 & $2.2 \pm 0.2$ & $8.2 \pm 0.2$ \\
\hline
\end{tabular}

The values obtained for $\omega_{D}$ and $\omega_{E}$ are recorded in table Ir.

Table II - Values of the Debye frequency $\omega_{D}$ and of the Einstein frequency for ${ }^{119} \mathrm{Sn}$ in $\mathrm{Si}_{1-\mathrm{x}} \mathrm{Sn}_{\mathrm{x}}$ amorphous alloys

Te fact that $\delta_{\text {IS }}$ increases with $\mathrm{x}$ can be ascribed to the decrease in the number of p-like electrons concentrated in covalent bonds when the concentration of tin increases $/ 10,11 /$.

The values, obtained for $\omega_{\mathrm{E}}$ are consistent with the Einstein frequency $\omega_{\mathrm{E}} \sim 8.8 \times 10^{13} \mathrm{~S}^{-1}$ in pure silicon $/ 12 /$. The softening of the Debye frequency $\omega_{D}$ when the concentration of $\mathrm{Sn}$ increases can be attributed to the weakening of the force constants for ${ }^{119} \mathrm{Sn}$ in $\mathrm{Si} / 12 /$ and to the presence of impurity modes around $\omega_{\ell} \sim 1.2 \times 10^{13} \mathrm{~s}^{-1}$. Detailed calculations of the vibration spectra in ordered $\mathrm{Si}_{50} \mathrm{Sn}_{50}$ crystalline alloys are currently in progress, to obtain values of the interatomic force constants.

\section{REFERENCES}

/1/ Polk, D. E., J. Non-Cryst. Solids, 5 (1971) 365.

Polk, D. E. and Boudreaux, D. S., Phys. Rev. Lett., 31 (1973) 92.

/2/ Comell, G. A., and Tenkin, R. J., Phys. Rev. B 9 (1974) 5323.

13/ Dixmier, J., Gheorghiu, A. and Theye, M. L., J. Phys. C 17 (1984) 227.

14/ Etherington, G., Wright, A. C., Wenzel, J. T., Dore, J. C., Clarke, J. H. and Sinclair, R. N., J. Non-Cryst. Solid.s, 48 (1982) 265.

Sinclair, R. N., Desa, J. A. E., Etherington, G., Johnson, P. A. V. and Wright, A. C., J. Non-Cryst. Solids 42 (1980) 107.

/5/ Vérié, C., Rochette, J, F. and Rebouillat, J. P., J. Phys. Paris 10 C 4 (1981) 667.

/6/ Vérié, C., Proc. 17th I. E. E. E., PVSC (to be published).

/7/ Williamson, D. L. and Deb, S. K., J. Appl. Phys. 54 (1983) 2588.

/8/ Vergnat, M., Thesis (1983) Nancy (unpublished).

Vergnat, M., Marchal, G., Piecuch, M., Gerl, M., Solid St. Corm. 50 (1984) 237.

19/ Vergnat, M., Piecuch, M., Marchal, G., and Gerl, M., Philos. Mag. 51 (1985) 327.

/10/ Antonitik, E., Phys. Stat. Sol. (b) 79 (1977) 605.

11/ Weyer, G., Nylandsted-Larsen, A., Deutch, B. I., Andersen, J. V., and Antoncik, E., Hyperfine Interactions, 1 (1975) 93.

/12/ Nielsen, O. H., Phys. Rev. B 25 (1982) 1225. 